\title{
Studi Kinerja VANET Scenario Generators: SUMO dan VanetMobisim untuk Implementasi Routing Protocol AODV menggunakan Network Simulator 2 (NS-2)
}

\author{
Firdaus Nutrihadi, Radityo Anggoro, dan Royyana Muslim Ijtihadie \\ Teknik Informatika, Fakultas Teknologi Informasi, Institut Teknologi Sepuluh Nopember (ITS) \\ Jl. Arief Rahman Hakim, Surabaya 60111 Indonesia \\ e-mail:onggo@if.its.ac.id
}

\begin{abstract}
Abstrak - Vehicular Ad Hoc Network (VANET) merupakan turunan dari MANET (Mobile Ad Hoc Network) sebagai inovasi baru dalam dunia teknologi yang membantu kebutuhan manusia dalam berkomunikasi. VANET dapat mendukung komunikasi langsung antara kendaraan (Vehicle to Vehicle) dan antara kendaraan-infrastruktur (Vehicle to Infrastructure) dengan adanya infrastruktur jaringan nirkabel. Namun, implementasi VANET di dunia masih sulit dilakukan sehingga banyak penelitian dilakukan dengan membuat simulasi menggunakan mobility generator dan network simulator. Pada makalah ini yang diteliti yaitu performa skema VANET yang dihasilkan oleh mobility generator SUMO dan Vanetmobisim. Penelitian ini menggunakan NS-2 sebagai simulator VANET dengan protokol reaktif AODV sebagai routing protocol.

Skenario VANET dengan peta berbentuk grid dan peta riil Sutomo,Surabaya digunakan pada kedua generator SUMO dan VanetMobisim dengan memvariasikan jumlah kendaraan simulasi. Matriks evaluasi kinerja yang digunakan dalam penelitian ini adalah packet delivery ratio, end-to-end delay, dan routing overhead. Dalam ketiga skenario, performa routing protokol SUMO-AODV lebih baik. VanetMobisim-AODV, dikarenakan lebih banyak lalu lintas dan rute yang putus,menghasilkan performa yang baik namun masih di bawah pesaingnya.
\end{abstract}

Kata Kunci-VANET, SUMO, VanetMobisim, AODV, NS-2.

\section{PENDAHULUAN}

SAAT ini perkembangan teknologi informasi dan

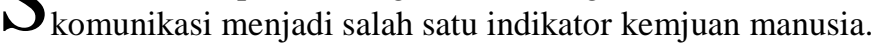
Salah satu teknologi yang membantu manusia dalam berkomunikasi dengan mudah adalah Vehicular Ad Hoc Network (VANET). VANET termasuk dalam jaringan komunikasi nirkabel dan merupakan subkelas dari Mobile Ad Hoc Network (MANET). Jaringan VANET adalah suatu jaringan Ad Hoc yang digunakan untuk berkomunikasi antara kendaraan satu dengan kendaraan lainnya dengan kata lain disebut juga dengan vehicle to vehicle communication (V2V).

Implementasi VANET dapat dilakukan dengan menggunakan simulasi sehingga penelitian ini dapat dilakukan untuk mempelajari sistem dengan baik. Simulasi dilakukan dengan menggunakan Network Simulator 2 (NS-2), salah satu simulator untuk jaringan VANET. Implementasi VANET di dunia nyata membutuhkan biaya yang sangat mahal dan jangkauan luas sehingga tidak memungkinkan untuk diimplementasikan secara langsung.

Dalam sebuah jaringan, protokol routing merupakan hal yang sangat berpengaruh terhadap kinerja jaringan tersebut. Begitu pula dalam jaringan VANET, terdapat banyak protokol routing yang dapat diimplementasikan pada jaringan ini. Salah satunya adalah protokol routing AODV (Ad hoc On demand Distance Vector). Pada makalah ini, penulis menggunakan simulator SUMO dan VanetMobisim untuk dianalisis kinerjanya dalam implementasi protokol routing AODV yang akan diintegrasikan menggunakan NS-2.

Alasan digunakan SUMO dan VanetMobisim ialah kedua generator ini masing-masing dapat mengimplementasikan skenario VANET ke dalam NS-2. Skenario VANET yang dimaksud berupa peta hasil generate baik berbentuk grid maupun peta nyata, kecepatan kendaraan, dan traffic light serta berbagai fitur yang mendukung kinerja simulasi VANET. Kedua generator ini banyak digunakan oleh para peneliti untuk menguji skema VANET.

Makalah ini membahas tentang studi kinerja dari skema VANET terhadap 2 generator, yaitu SUMO dan VanetMobisim dengan hasil akhir yang diharapkan adalah untuk mengetahui perbandingan kinerja jaringan VANET dalam beberapa skenario (peta berbentuk grid dan peta riil). Sedangkan manfaat yang ada pada pembuatan makalah ini adalah untuk menentukan konfigurasi yang tepat untuk menghasilkan skenario realistik pada VANET untuk implementasi protokol routing AODV. Adapun efisiensi protokol routing AODV diukur berdasarkan beberapa metrik performansi, yaitu Packet Delivery Ratio (PDR), End-to-End Delay pengiriman, dan Routing Overhead.

\section{II.URAIAN PENELITIAN}

\section{A. Vehicle Ad hoc Network (VANET)}

Sejumlah kendaraan yang terhubung satu sama lain melalui sebuah rangkaian ad hoc membentuk suatu jaringan nirkabel yang disebut Vehicular Ad hoc Network. Vehicular Ad Hoc Network (VANET) merupakan kategori khusus dari mobile ad hoc networks (MANET's), ditandai dengan mobilitas tinggi dan konektivitas yang rendah. 


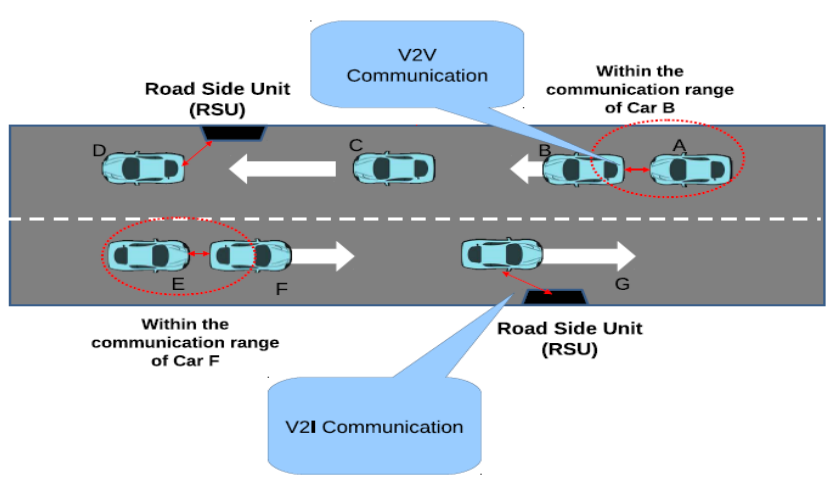

Gambar 1. Skema VANET [11]

VANET juga dapat dikatakan sebagai sebuah jaringan terorganisir yang dibentuk dengan menghubungkan antar kendaraan dan RSU (Road Side Unit). Lebih lanjut RSU terhubung ke jaringan backbone berkecepatan tinggi melalui koneksi jaringan.

Kepentingan peningkatan baru-baru ini telah diajukan pada aplikasi melalui komunikasi V2V (Vehicle to Vehicle) dan V2I (Vehicle to Infrastructur), bertujuan untuk meningkatkan keselamatan mengemudi dan manajemen lalu lintas sementara bagi para pengemudi dan penumpang. Dalam VANET, RSU (Road Side Unit) dapat memberikan bantuan dalam menemukan fasilitas seperti restoran dan pom bensin serta mem-broadcast pesan yang terkait seperti kecepatan kendaraan kepada pengendara lain [1]. Sebagai contoh sebuah kendaraan dapat terhubung dengan lampu lalu lintas melalui komunikasi V2I dan lampu lalu lintas dapat memberikan informasi ke kendaraan ketika dalam keadaan lampu ke kuning atau merah. Ini dapat berfungsi sebagai tanda pemberitahuan kepada pengemudi dan akan sangat membantu para pengendara ketika mereka sedang berkendara selama kondisi cuaca buruk atau di daerah asing. Hal ini dapat mengurangi terjadinya kecelakaan. Melalui komunikasi V2V, pengendara bisa mendapatkan informasi yang lebih cepat dan lebih baik serta mengambil tindakan awal untuk menghadapi situasi yang abnormal. Untuk mencapai hal ini, suatu OBU (On-Board Unit) secara teratur menyiarkan pesan yang terkait dengan informasi dari posisi pengendara, waktu sekarang, arah pengemudian, kecepatan, status rem, lampu sen, percepatan/perlambatan, kondisi jalan [2].

\section{B. Protokol Routing Ad hoc On-demand Distance Vector (AODV)}

AODV merupakan protokol routing yang bersifat ondemand. AODV termasuk kedalam klasifikasi routing protocol reaktif, yang hanya melakukan request sebuah rute saat dibutuhkan. Protokol routing ini dikembangkan oleh C. Perkins, E. Belding-Royer and S. Das tahun 2003 pada RFC 3561. Route Request (RREQ), Route Reply (RREP), and Route Error (RERR) adalah jenis-jenis pesan yang didefinisikan oleh AODV. Jenis pesan ini diterima melalui UDP.

AODV merupakan sebuah protokol routing dan berhubungan dengan manajemen tabel rute. Informasi tabel rute harus disimpan bahkan untuk rute pendek. AODV menggunakan field-field berikut dengan setiap entri tabel rute:

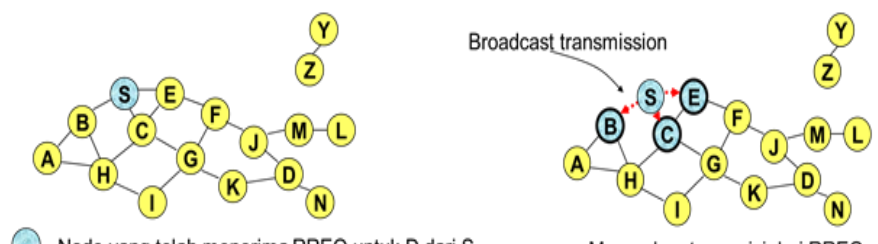

Node yang telah menerima RREQ untuk $D$ dari $S$

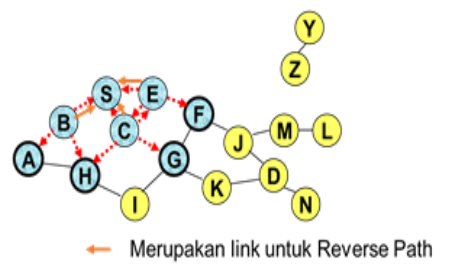

..... Merupakan transmisi dari RREQ

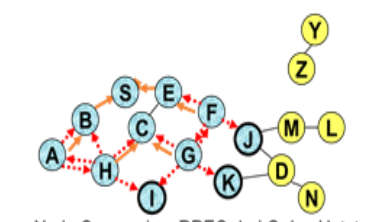

-Node $\mathrm{C}$ menerima RREQ dari $\mathrm{G}$ dan $\mathrm{H}$, tetap tidak melakukan forward lagi, karena node $\mathrm{C}$ sudah pernah melakukan forward RREQ sekali
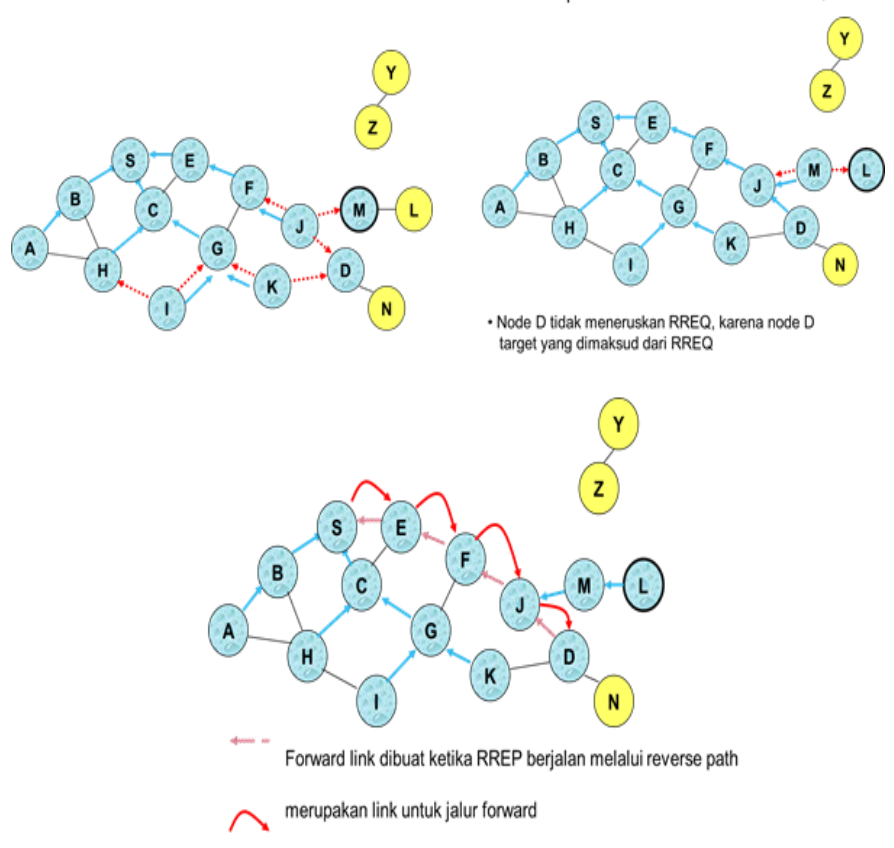

Gambar 2.Teknik pencarian rute dari AODV [3]

- Destination IP Address: berisi alamat IP dari node tujuan yang digunakan untuk menentukan rute.

- Destination Sequence Number : destination sequence number bekerjasama untuk menentukan rute

- Next Hop: 'Loncatan' (hop) berikutnya, bisa berupa tujuan atau node tengah, field ini dirancang untuk meneruskan paket ke node tujuan.

- Hop Count: Jumlah hop dari alamat IP sumber sampai ke alamat IP tujuan.

- Lifetime: Waktu dalam milidetik yang digunakan untuk node menerima RREP.

- Routing Flags: Status sebuah rute; up (valid), down (tidak valid) atau sedang diperbaiki [1].

\section{Simulation of Urban Mobility (SUMO)}

Simulation of Urban Mobility atau biasa dikenal dengan SUMO merupakan sebuah program open source simulator lalu lintas jalan yang memungkinkan pengguna untuk membangun simulasi pergerakan kendaraan pada topologi jaringan VANET yang disesuaikan. Pengimplementasian SUMO dimulai pada tahun 2001, dengan sebuah rilis open source tahun 2002, dikembangkan oleh Daniel Krajzewicz, Jakob Erdmann, Michael Behrisch, and Laura Bieker [4]. 
SUMO terdiri dari banyak tools yang memiliki fungsi yang berbeda. Berikut merupakan penjelasan beberapa fungsi tools yang dipakai guna mendukung pembuatan makalah ini:

- netgenerate.exe

- netconvert.exe

- randomTrips.py

- duarouter.exe

- sumo-gui.exe

- sumo.exe

- traceExporter.py

\section{VanetMobisim}

VanetMobisim adalah sebuah ekstensi untuk CANU Mobility Simulation Environtment (CanuMobisim), sebuah kerangka kerja yang fleksibel untuk pemodelan mobilitas pengguna. VanetMobisim berbasis Java dan dapat melakukan generate jejak pergerakan dalam format yang berbeda, mendukung simulasi/emulasi yang berbeda untuk jaringan mobile (NS-2, Glomosim, QualNet). Awalnya VanetMobisim meliputi parser untuk standar peta di Geographical Data Files (GDF) dan menyediakan implementasi dari beberapa model mobilitas acak serta model dari dinamika fisika dan kendaraan.

Vanetmobisim memantau pergerakan dari kendaraan baik pergerakan makro maupun representasi pergerakan mikro untuk menentukan model dari pergerakan dalam simulasi. Mobilitas makro mencakup topologi jalan, struktur jalan (misal, uni-bi directional, single-multilane), batas kecepatan, dan keberadaan lampu lalu lintas. Konsep dari mobilitas mikro mencakup semua aspek yang berhubungan dengan interaksi antarkendaraan dan antar kendaraan-infrastruktur [5].

Karakteristik VanetMobisim adalah sebagai berikut.

- VanetMobiSim adalah sebuah open source mobility model generator

- Spesifik untuk VANET

- Platform Independent Software

- Mendukung spesifikasi mobilitas makro dan mikro

- Menggunakan XML Code untuk menentukan simulasi yang berbeda

- Telah divalidasi [6]

\section{E. OpenStreetMap}

OpenStreetMap adalah sebuah proyek kolaboratif berbasis web untuk membuat dan membangun peta geografis seluruh dunia secara gratis dan terbuka, dibangun sepenuhnya oleh sukarelawan dengan melakukan survei dan mengumpulkan data menggunakan perangkat GPS, fotografi udara, dan sumber bebas lainnnya, dimanfaatkan untuk beragam kebutuhan termasuk navigasi. Siapapun dapat berkontribusi untuk OSM. OpenStreetMap dirintis pertama kali oleh Steve Coast di Britania Raya pada tahun 2004 [7].

\section{F. JOSM}

Java OpenStreetMap Editor atau biasa disingkat JOSM merupakan sebuah aplikasi desktop berbasis Java dan dapat dioperasikan pada sistem operasi seperti Windows, Mac OS, dan Linux. JOSM adalah alat penyunting bagi data OpenStreetMap. JOSM pertama kali dikembangkan oleh
Immanuel Scholz pada tahun 2005 [8]. Aplikasi ini tidak membutuhkan koneksi internet kala menyunting data OSM, sedangkan situs untuk mengunduhnya dapat diakses di josm.openstreetmap.de untuk mendapatkan versi terbaru dari aplikasi ini.

\section{G. $A W K$}

AWK adalah sebuah bahasa pemrograman yang biasanya digunakan sebagai ekstraksi data dan alat pelaporan. AWK diciptakan di Bell Labs pada Tahun 1970, dan merupakan singkatan dari nama belakang penciptanya, yaitu Alfred Aho, Peter Weinberger, dan Brian Kernighan. AWK atau juga disebut Gawk (GNU awk). AWK biasanya digunakan untuk analisi $\log$ yang panjang atau grab teks lalu dimodifikasi dengan hanya beberapa baris kode [9].

\section{H.Network Simulator 2 (NS-2)}

Network Simulator 2 atau biasa disingkat NS-2 merupakan sebuah network simulator yang dibuat dengan tujuan riset dan pendidikan. Awalnya, NS dibangun sebagai varian dari REAL Network Simulator pada tahun 1989 di UCB (University of California Berkeley) [10].

NS-2 merupakan salah satu perangkat lunak yang dapat menampilkan secara simulasi proses komunikasi dan bagaimana proses komunikasi tersebut berlangsung. NS-2 melayani simulasi untuk komunikasi dengan kabel dan nirkabel. NS-2 memiliki beberapa fitur kelebihan yang dapat dimanfaatkan dalam pemodelan dan pengujian VANET. NS-2 memiliki tools validasi yang berfungsi untuk menguji validitas pemodelan yang ada pada NS-2. NS-2 bersifat open source dibawah GPL (GNU Public Licence), sehingga dapat diunduh melalui situs NS-2 di http://www.isi.edu/nsnam/dist.

\section{PERANCANGAN}

\section{A. Deskripsi Umum}

Pada paper ini, akan dilakukan analisis mengenai performansi metrik (Packet Delivery Ratio, End-to-End Delay, Routing Overhead) pada dua generator, yaitu SUMO dan VanetMobisim dalam pengimplementasian routing protocol AODV. Tahapan rancangan simulasi dapat dilihat pada Gambar 3.

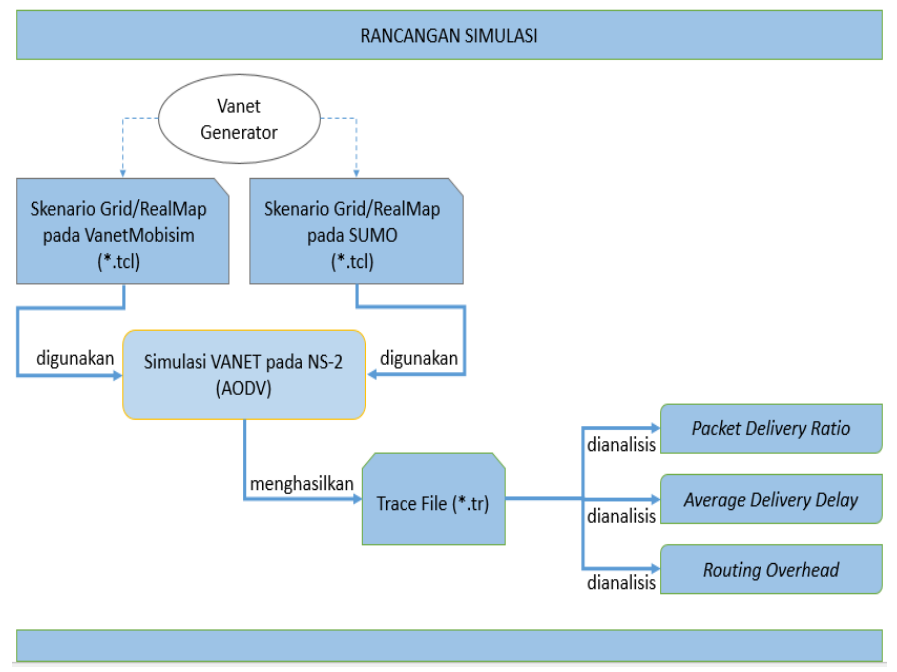

Gambar 3. Tahapan Rancangan Simulasi 


\section{B. Perancangan Skenario}

Perancangan skenario mobilitas ujicoba VANET dimulai dari perancangan peta pergerakan node, pembuatan rute lalu lintas dan pengimplementasian pergerakan. Dalam paper ini, bagian perancangan peta pergerakan node menggunakan dua skenario peta, yakni peta grid dan peta riil. Peta grid adalah peta yang berupa serangkaian jalan saling berpotongan dan membentuk persegi. Peta grid ini menggambarkan lingkungan riil dalam bentuk yang sederhana. Peta ini digunakan sebagai tes awal implementasi dikarenakan peta grid seimbang dan stabil. Sedangkan pada peta riil, digambarkan sebuah lingkungan lalu lintas yang nyata. Pada penelitian ini, digunakan lingkungan lalu lintas di daerah Sutomo, Surabaya sebagai peta riil. Peta riil yang dimaksud hanya berupa jalurjalur tanpa adanya infrastruktur.

\section{Pembuatan peta pada SUMO}

\section{a) Pembuatan peta grid}

Pembuatan peta grid diawali dengan menentukan ukuran peta yang digunakan (panjang dan lebar). Setelah menentukan ukuran, langkah selanjutnya ialah menentukan jumlah grid yang akan dibuat. Pada penelitian ini, digunakan peta yang berukuran $1500 \mathrm{~m}$ x $1500 \mathrm{~m}$ dan jumlah grid sebanyak 11 . Alur pembuatan peta grid dapat dilihat pada

\section{b) Pembuatan peta riil}

Tahap awal pembuatan peta riil ialah dengan mencari daerah real world yang mendekati bentuk grid dan dengan mobilitas yang tinggi sehingga cocok untuk jaringan VANET. Pada penelitian ini, diperoleh daerah Sutomo,Surabaya sebagai objek peta riil. Proses pembentukan skenario diawali dengan menggunakan OpenStreetMap untuk melakukan capture peta. Selanjutnya dilakukan proses pengeditan pada peta hasil capture menggunakan aplikasi JOSM, agar peta dapat berjalan dengan baik saat simulasi.

\section{Pembuatan peta pada VanetMobisim}

\section{a) Pembuatan peta grid}

Pembuatan peta grid pada VanetMobisim dilakukan secara manual. Berbeda dengan SUMO, pada VanetMobisim tidak terdapat tools untuk membuat peta grid seperti "netgenerate", sehingga satu-satunya cara ialah dengan membuat dari awal peta grid menggunakan tools yang disediakan, yaitu fitur Select,Marquee (tools untuk memilih node atau jalur), Junction (membuat sebuah tikungan atau persimpangan), dan Road Element (membuat sebuah elemen jalan)

\section{b) Pembuatan peta riil}

Tahapan awal pembuatan peta riil pada VanetMobisim ialah dengan melakukan import data dari OpenStreetMap dimana terdapat fitur khusus untuk melakukan import ini. Terdapat dua cara import, pertama dengan meng-import langsung melalui aplikasi VanetMobisim. Pada menu OpenStreetMap di dalam VanetMobisim, dapat dipilih secara langsung daerah mana yang akan di-import.

\section{Perancangan Simulasi pada NS-2}

Pada perancangan kode NS-2 dengan konfigurasi VANET, dilakukan penggabungan skenario mobilitas dengan skrip Tcl yang dihasilkan saat pembuatan skenario selesai. Berikut perancangan sistem VANET untuk NS-2 yang ditunjukkan oleh Tabel 1.

\begin{tabular}{|c|c|c|}
\hline No. & Parameter & Spesifikasi \\
\hline 1 & Network Simulator & NS-2 versi 2.35 \\
\hline 2 & Routing Protocol & AODV \\
\hline 3 & Waktu Simulasi & 500 detik \\
\hline 4 & Area Simulasi & $1500 \mathrm{~m} \times 1500 \mathrm{~m}$ \\
\hline 5 & Jumlah Kendaraan (node) & $50,75,100$,dan 125 \\
\hline 6 & Radius Transmisi & $250 \mathrm{~m}$ \\
\hline 7 & Kecepatan maksimal & $15 \mathrm{~m} / \mathrm{s}$ \\
\hline 8 & Tipe Data & Constant Bit Rate (CBR) \\
\hline 9 & Source / Destination & Statik (node_1 ke node_0) \\
\hline 10 & Interval Paket & 1 paket per detik \\
\hline 11 & Ukuran paket data & 64 bytes \\
\hline 12 & Protokol MAC & IEEE $802.11 \mathrm{p}$ \\
\hline 13 & Modul Propagasi & TwoRay-Ground \\
\hline 14 & Model Skenario & $\begin{array}{c}\text { Peta Grid dan Peta Riil } \\
\text { Sutomo }\end{array}$ \\
\hline 15 & Tipe Kanal & Wireless Channel \\
\hline
\end{tabular}

\section{PENGUJIAN DAN EVALUASI}

\section{A. Kriteria Pengujian}

Pengujian pada generator SUMO dan VanetMobisim menggunakan kriteria atau patokan yang sama. Pada Tabel 2. berikut menunjukkan kriteria-kriteria yang ditentukan didalam skenario.

Tabel 2. Kriteria Pengujian

\begin{tabular}{|l|l|}
\hline Kriteria & Spesifikasi \\
\hline Jumlah Node & $50,75,100,125$ \\
\hline Kec. Maks Node (m/s) & 15 \\
\hline Percobaan & 10 percobaan per jumlah node \\
\hline Pergerakan & Random (Acak) \\
\hline Posisi Awal Node & Random (Acak) \\
\hline Output & *.tcl \\
\hline
\end{tabular}

\section{B. Analisis Packet Delivery Ratio}

Grafik pada Gambar 4. dapat diamati bahwa performansi matriks Packet Delivery Ratio dari routing protocol AODV pada SUMO (garis biru) lebih baik dibandingkan dengan perfomansi routing protocol AODV pada VanetMobisim (garis merah). Nilai PDR yang diperoleh untuk keduanya berkisar antara 20\%-80\%. Untuk setiap kepadatan node bertambah, nilai dari PDR semakin meningkat dikarenakan paket yang terkirim tidak mengalami broken link, sehingga pengiriman paket data lebih banyak yang berhasil. Kedua performa generator mengalami penurunan ketika jumlah kendaraan atau node 125 meskipun tidak terlalu signifikan, yaitu sebesar $4.67 \%$ pada SUMO dan $5.67 \%$ pada VanetMobisim.

Grafik pada Gambar 5. menunjukkan performansi matriks PDR yang menggunakan routing protocol AODV pada skenario riil cenderung bernilai konstan antara 40\%-80\% dan stabil seiring dengan bertambahnya jumlah kendaraan atau node.

Naiknya performa protokol AODV pada masing-masing generator seiring bertambahnya kepadatan node disebabkan oleh jarak antar kendaraan atau node semakin kecil dan kemungkinan putusnya komunikasi antar kendaraan sekitar juga mengecil. 


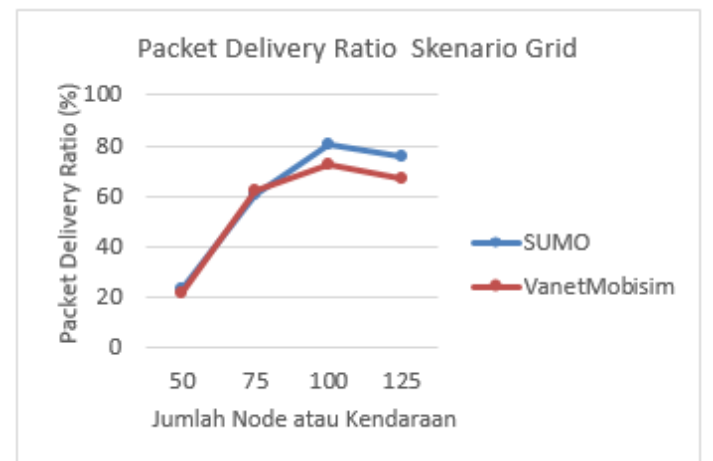

Gambar 4. Grafik Packet Delivery Ratio Skenario peta grid

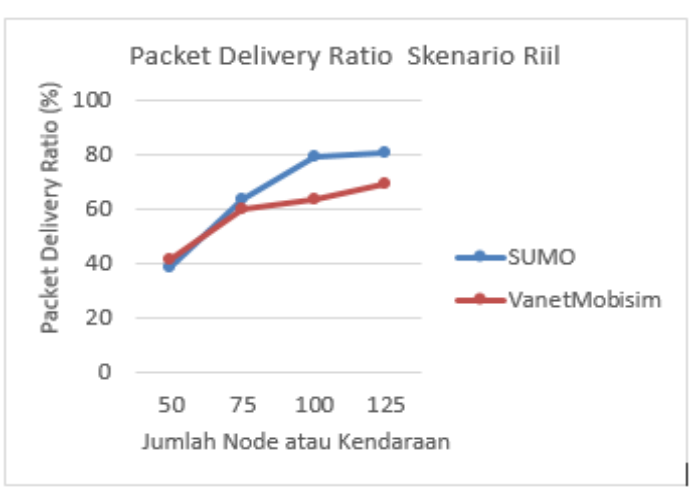

Gambar 5. Grafik Packet Delivery Ratio Skenario peta riil

Akan tetapi pada jumlah node 125 routing protocol mengalami penurunan performa, hal ini terjadi dikarenakan terjadi queue pada node penghubung sehingga paket data yang dapat dilewatkan hilang karena terlalu lama queue yang terjadi pada node penghubung tersebut. Life time sebuah paket akan habis masa waktunya sehingga paket akan di drop.

\section{C.Analisis End-to-End Delay}

Grafik pada Gambar 6. dapat diketahui performa Delay pada skenario peta grid untuk SUMO dibandingkan dengan VanetMobisim dan dari grafik ini juga dapat dilihat bahwa semakin padat sebuah jaringan maka semakin kecil nilai delay-nya. Pada jumlah node 50 delay yang terjadi hampir mencapai 3 detik pada SUMO. Peningkatan performa delay pada SUMO ditandai dengan semakin kecil nilai delay yang dihasilkan secara konstan menurun (lihat grafik). Karena semakin padatnya jaringan maka paket data yang dikirim mengalami queue dan saat node terputus koneksinya, maka kemungkinan node akan mem-broadcast pesan Error ke node tetangga dan dapat membuat delay serta paket drop. Namun, seiring bertambahnya kepadatan node maka pencarian rute yang terjadi akan lebih cepat sehingga delay dapat dikurangi.

Grafik pada Gambar 7. diketahui performa End-to-End Delay pada skenario riil untuk SUMO dan VanetMobisim mengalami perbedaan satu sama lain seiring dengan bertambahnya jumlah kendaraan. Routing protocol AODV pada SUMO memberikan performa yang lebih baik dibandingkan routing protocol AODV pada VanetMobisim. Grafik dengan arah menurun dari kiri ke kanan menandakan peningkatan performa berdasarkan jumlah node. Peningkatan performa delay pada SUMO terjadi pada jumlah node 75 dan jumlah node 125. Namun, penurunan performa terjadi pada jumlah node 50 dan 100. Sedangkan peningkatan performa delay pada VanetMobisim meningkat cenderung stabil namun

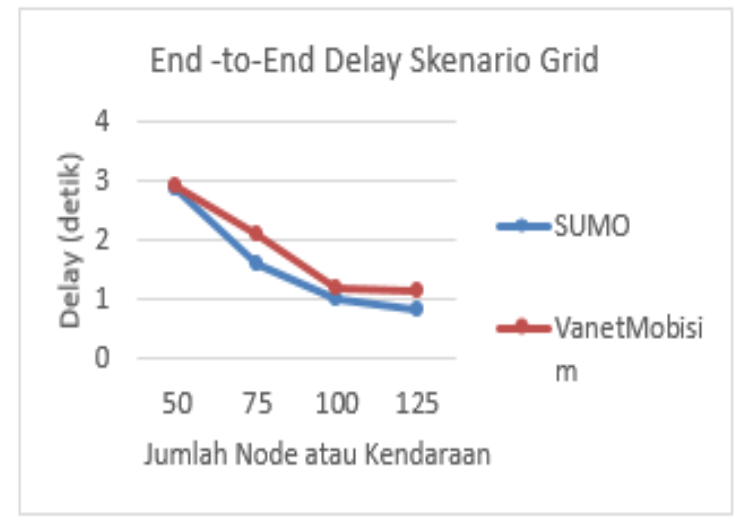

Gambar 6. Grafik End-to-End Delay Skenario peta grid

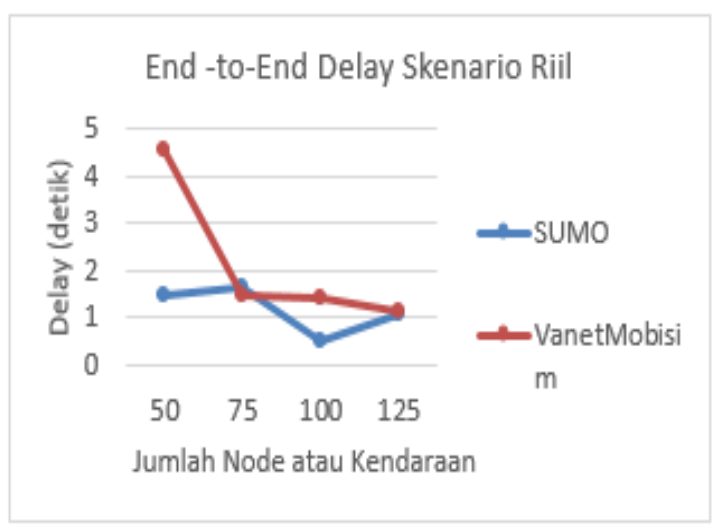

Gambar 7. Grafik End-to-End Delay Skenario peta riil

perbedaan delay antara jumlah node 75 dengan jumlah node 100 nilainya kecil sebesar 0.05 detik. Namun kenaikan performa menanjak tajam ketika jumlah kendaraan atau node 75 unit sebesar 3.04 detik.

Delay yang besar terjadi pada VanetMobisim dikarenakan adanya rute-rute putus serta terjadinya queue sehingga menyebabkan data yang dikirim mengalami delay yang lama. Tidak hanya itu, pergerakan node yang dibuat secara acak dapat membuat packet drop. Dari grafik sebelumnya, dapat dilihat bahwa nilai delay pada skenario peta grid pada SUMO dan VanetMobisim cenderung bernilai kecil. Perbedaannya menunjukkan performa delay pada VanetMobisim lebih baik daripada SUMO. Nilai delay pada skenario riil pada SUMO dan VanetMobisim mengalami perubahan yang unik. Adanya kenaikan dan penurunan performa pada SUMO pada setiap variabel jumlah node. Namun, sama seperti pada peta grid, performa delay pada SUMO tetap lebih baik dibandingkan VanetMobisim.

\section{D.Analisis Routing Overhead}

Pada pengujian skenario peta grid dengan menggunakan SUMO dan VanetMobisim serta variasi jumlah kendaraan menunjukkan nilai Routing Overhead pada VanetMobisim naik secara signifikan dan tajam seiring dengan penambahan jumlah kendaraan dalam simulasi. Sementara SUMO mengalami kenaikan yang stabil (Gambar 8). Untuk pengujian Routing Overhead pada skenario riil dengan peta Surabaya juga mengalami kondisi yang sama seperti skenario grid dimana VanetMobisim mengalami kenaikan paket routing yang tinggi dan stabil sementara SUMO mengalami kenaikan paket routing yang cenderung stabil (Gambar 9). 


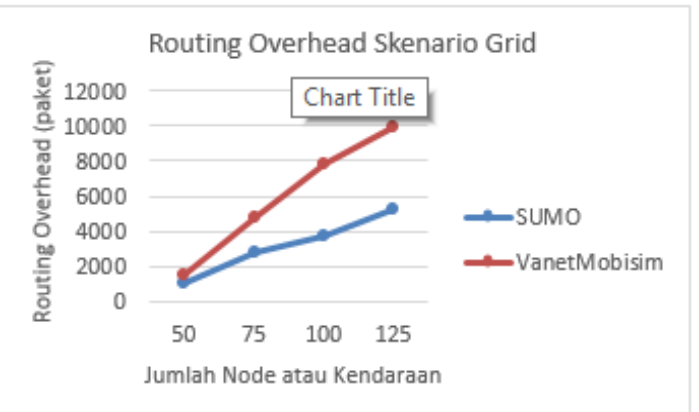

Gambar 8. Grafik Routing Overhead Skenario peta riil

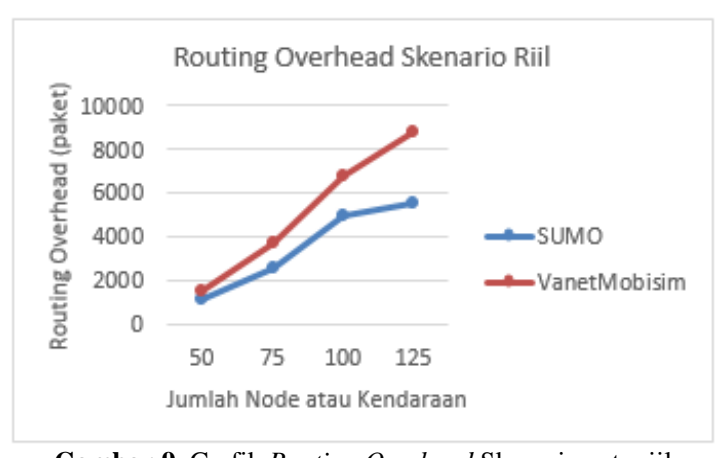

Gambar 9. Grafik Routing Overhead Skenario peta riil

Dari grafik diatas dapat diamati bahwa semakin padat jaringan maka semakin tinggi Routing Overhead yang terjadi dikarenakan banyaknya node-node penghubung yang harus dilewati oleh sebuah paket untuk mencapai tujuan. Perbedaan dan pergerakan posisi node saat terjadi pengiriman paket menyebabkan nilai Routing Overhead pada routing protocol AODV di SUMO lebih baik daripada VanetMobisim.

Hasil analisis yang dilakukan pada metrik-metrik diatas menyebabkan perbedaan diantara kedua generator, yaitu SUMO dan VanetMobisim. Faktor-faktor yang menyebabkan adanya perbedaan ini mengacu pada lokasi dan pergerakan pada node serta delay-delay yang terjadi. Pada analisis PDR dan RO, salah satu faktor yang dapat menyebabkan perbedaan hasil analisis yaitu Packet Drop. Packet Drop mempengaruhi kedua matriks tersebut karena semakin banyak paket yang drop maka nilai PDR nya pun akan semakin rendah. Semakin tingginya nilai RO maka packet drop semakin rendah dikarenakan pencarian rute lebih cepat dilakukan seiring bertambahnya kepadatan node. Untuk kepadatan jaringan yang sedikit menyebabkan drop paket semakin besar.

\section{V.KESIMPULAN DAN SARAN}

Kesimpulan yang diperoleh dari uji coba dan evaluasi adalah sebagai berikut:

1. Protokol AODV memiliki performa yang tidak stabil pada VanetMobisim secara keseluruhan dan lebih rendah dibanding SUMO.

2. Routing Overhead meningkat seiring dengan bertambahnya jumlah kendaraan dalam skenario. Apabila dihubungkan dengan PDR, hasil RO berbanding terbalik dengan hasil PDR. Nilai PDR yang semakin besar memberikan RO yang semakin kecil.

3. Faktor yang mempengaruhi performansi pada jaringan ini adalah kepadatan node dan penempatan node tersebut. Faktor lainnya yang membedakan SUMO dan
VanetMobisim adalah posisi awal node dan pergerakan node yang diatur secara acak menyebabkan perjalanan paket-paket pada VanetMobisim sehingga dapat mengalami queue dan packet drop serta dengan rumitnya pencarian rute menyebabkan delay yang saat pengiriman paket ke node tujuan. Packet Drop ini menyebabkan perbedaan pada nilai PDR dan RO.

4. Perlu dilakukan modifikasi pre-processing terhadap mobilitas saat melakukan simulasi di dalam SUMO dan VanetMobisim agar adaptif terhadap perubahan mobilitas tinggi dan densitas kendaraan dalam lingkungan VANET.

5. Perlu dilakukan perubahan dan penambahan skema traffic light di dalam kedua generator untuk skenario peta riil Surabaya yang dimuat pada OpenStreetMap karena masih memiliki kesalahan dalam implementasi skenario nyata Surabaya.

6. Penelitian lebih lanjut dapat dilakukan terhadap VANET menggunakan NS2 beserta implementasi nyata pada kendaraan agar VANET benar-benar bisa diimplementasikan kedepannya.

\section{UCAPAN TERIMA KASIH}

Penulis mengucapkan terima kasih kepada orang tua, keluarga, dosen pembimbing, dosen penguji, dan pihak-pihak lain yang secara langsung maupun tidak langsung telah membantu dalam menyelesaikan tulisan ini.

\section{DAFTAR PUSTAKA}

[1] Arifin, M. S. Hadi, H. Amran and N. P. R, "Analisis Performansi Routing AODV pada Jaringan VANet", Surabaya: ITS, 2011.

[2] H. J. Zygmunt, M. R. Pearlman and P. Samar, "The Zone Routing Protocol (ZRP) for Ad Hoc Networks, New York": Cornell University, 2002.

[3] Sridhar Iyer, "Mobile Ad Hoc Networks," 20 December 2000. [Online]. Available: http://www.it.iitb.ernet.in.in/ sri. [Accessed 15 Nopember 201

[4] M. Behrisch, L. Bieker, J. Erdmann and D. Krajzewicz, "SUMO Simulation of Urban MObility", Berlin: German Aerospace Center, 2009.

[5] "VanetMobiSim Project," [Online]. Available: http:// vanet.eurecom.fr.. [Accessed 29 Oktober 2015].

[6] J. Haerri, F. Filali and C. Bonnet, "VanetMobiSim: Generating Realistic Mobility Patterns for VANETs," pp. 96-97, 2006.

[7] "Gudang Linux," OpenStreetMap, 22 December 2013. [Online]. Available: http://gudanglinux.com/glossary/open streetmap/. [Accessed 30 November 2015].

[8] "Acordocoletivo," JOSM, 15 January 2011. [Online]. Available:http://wiki.openstreetmap.org/wiki/JOSM.[Accessed 30 November 2015].

[9] A. D. Robbins, "GAWK: Effective AWK Programming", Boston: Free Software Foundation, 2015.

[10] T. Issariyakul and E. Hossain, "Introduction to Network Simulator NS2", Bangkok: Springer Science+Business Media, 2009.

[11] G. Singh, N. Chakrabarty and K. Gupta, "Traffic Congestion Detection and Management Using Vehicular Ad-Hoc Networks (VANETs) In India," International Journal of Advanced Computer Technology (IJACT), vol. 3, p. 24, 2014. 